\title{
Effect of Water Stress on Yield and Seed Quality of Coriander (Coriandrum sativum L.)
}

\author{
Priyanka Thakur ${ }^{1 *}$ and Anju Thakur ${ }^{2}$
}

${ }^{1}$ Dept. of Seed Science and Technology, ${ }^{2}$ Dept. of Basic Sciences, Dr. Y. S. Parmar University of Horticulture and Forestry, Nauni, Solan, H.P. (173 230), India

\author{
Corresponding Author \\ Priyanka Thakur \\ e-mail: priyankathakur117@gmail.com
}

\author{
Article History \\ Article ID: 3 C0581 \\ Received in $26^{\text {th }}$ October, 2017 \\ Received in revised form $21^{\text {st }}$ December, 2017 \\ Accepted in final form $30^{\text {th }}$ January, 2018
}

\begin{abstract}
Coriander (Coriandrum sativum L.) is an annual herbaceous plant commonly known as Cilantro or Dhania, belonging to family Apiaceae (Umbelliferae), it is a powerful herb with many health benefits.It is a dual purpose crop grown for its aromatic leaves and cremocarpic seeds, which are extensively used as a spice and food flavouring agent. Plant growth is seriously affected by abiotic stresses and drought is one of the most important limiting factors. Drought stress during earlyreproductive growth stage usually reduces the seed yield and seed quality. To assess the effect of drought stress on seed yield and seed quality of coriander, the experiment was conducted in green house in plastic pots at Dr. Y.S. Parmar University of Horticulture and Forestry, Nauni, Solan (H.P.) during the Rabi season of 2012-13. Coriander cv. Solan Selection was used as a test crop. There were four treatments of Water stress i.e. $\mathrm{T}_{1}$-Control, $\mathrm{T}_{2}-25 \%, \mathrm{~T}_{3}-50 \%$, and T4-75\% Water deficit imposed at flower forming phase for 15 days. The treatments were arranged in a design CRD (Completely Randomized Design) with fourreplications. Data were recorded and results indicated the significant reduction in plant height stress index, dry matter index, biological yield, number of seeds per plant, harvest index ( $\mathrm{HI})$ and yield stability ratio and also observed per cent reduction in 1000- seed weight, seed moisture content and germination percentage. On other hand there where per cent increase in solute leakage, mean germination time.
\end{abstract}

Keywords: Biological yield, dry matter index, harvest index $(\mathrm{HI})$

\section{Introduction}

Coriander is an annual herb and according to the climatic conditions, it is cultivated as a summer or winter annual crop. It is a dual purpose crop grown for its aromatic leaves and cremocarpic seeds, which are extensively used as a spice and food flavouring agent (Singh and Singh, 1996). Its fresh leaves are used in salads, soups, vegetables etc. due to its aromatic flavor. The fruits are extensively employed as a condiment. Both leaves and seeds of the plant are used for medicinal purpose. In India, coriander is very popular for its anti-inflammatory proprieties. Individuals suffering from diabetes, as well as those with high cholesterol levels can benefit from using this herbal remedy. Coriander may also be used in treating muscle pain, headaches and stiffness. Coriander also has blood thinning proprieties. Its seeds can be used to prepare medical teas to treat indigestion. Coriander is also used in detoxifying diet. It helps to remove toxic mineral residue, such as mercury and lead and excretes them in the urine or faeces, (Leena et al., 2012).

In India the major coriander growing areas lie under semi-arid climate where the crop is cultivated on conserved moisture during rabi season requiring 2-3 irrigation depending upon soil condition and rainfall. In Himachal Pradesh, coriander is mainly grown under rained conditions; moreover, the rainfall is not well distributed throughout the year. Limited water supply is a major environmental constraint for higher productivity of crop plants including coriander (Coriandrum sativum L.). The availability of water to the mother plant during seed production is important because it affects seed yield and quality of many spices. In general, most of the research on water requirements of different crops has focused on optimizing yield of commodity products and only rarely considered seed yield or quality parameters. Effects of water stress on seed yield depend on the crop and will vary depending on the intensity, duration, and timing of the water deficit. In general, water stress before and during flowering has been observed to affect seed yield by reducing the number of seeds produced per plant. Hence, the available water has to be used very precisely so that maximum yield can be recovered without affecting the quality of seeds. Therefore the aim of this study was to determine the effect of water stress on the seed yield and quality of coriander under water stress conditions. 


\section{Materials and Methods}

The experiment was designed to observe the effect of water stress on seed yield and quality of Coriander cv. Solan Selection. The study was conducted in green house in plastic pots at Dr. Y.S. Parmar University of Horticulture and Forestry, Nauni, Solan (H.P.) during the Rabi season of 2012-13. There were four treatments of Water stress i.e. $T_{1}$-Control, $T_{2}-25 \%$, $\mathrm{T}_{3}-50 \%$, and $4-75 \%$ Water deficit imposed at flower forming phase for 15 days. The treatments were arranged in a design CRD (Completely Randomized Design) with four replications. Observation were recorded

\subsection{Plant height stress index:}

Plant height stress index was calculated as:

Plant height stress index=---
Plant height under non stress

\subsection{Biological yield}

Total weight of absolute ground biomass was taken in grams. It included all the parts of plants except roots. The weight was expressed in grams.

\subsection{Dry Matter stress index}

Dry matter stress index was calculated by recording the total dry matter produced under unstressed and stressed conditions at the end of experiment and it was calculated by the following formula:

$$
\begin{aligned}
& \text { Total dry matter produced } \\
& \text { under stress }
\end{aligned}
$$

Dry matter stress index

$$
\begin{aligned}
& \text { Total dry matter produced } \\
& \text { under control }
\end{aligned}
$$

\subsection{No. of seeds plant ${ }^{-1}$}

Number of seeds plant ${ }^{-1}$ was counted with the help of seed counter.

\subsection{Seed weight plant ${ }^{-1}$}

Seed weight was taken with the help of electronic balance and weight was expressed in $\mathrm{g}$.

\subsection{Yield stability ratio:}

Yield stability ratio was calculated by using the formula:

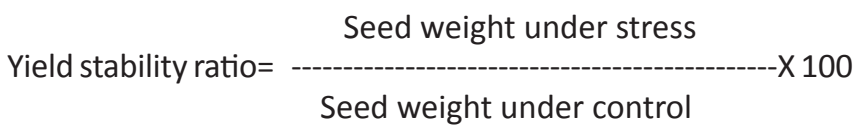

\subsection{Harvest index:}

Harvest index was calculated by using the following formula:

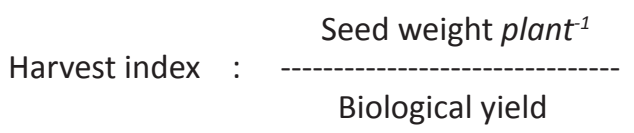

\subsection{Seed weight:}

Seed sample was taken randomly from each treatment and 1000 seeds were counted and weighed with an electronic balance and was expressed in grams.

\subsection{Seed moisture content}

Seed moisture was recorded with the help of non- destructive type of moisture meter according to the prescribed standard procedure and expressed as percentage (\%)

\subsection{Solute leakage}

electrical conductivity of seed leachates was determined by the use of method given by Hampton et al., 1994.

\section{Results and Discussion}

The effects of water deficit treatments on the yield and quality of seeds which were harvested from unstressed and stressed plants have been explained with the help of tables to follow.

\subsection{Plant height stress index}

The data presented in Table 1 exhibits the significant effects of different water stress levels on plant height stress index. The plant height stress index ranged from $94.05 \%$ to $80.34 \%$ among different water stress treatments over the control. The highest $(94.05 \%)$ plant height stress index was observed for plants subjected to $25 \%$ water stress and $90.11 \%$ for $50 \%$ water stressed plants. However, minimum (80.34\%) plant height stress index was calculated for the plants, which subjected to $75 \%$ water stress level. Water deficit conditions affect the water relations in plants and the water relation characteristics are most associated with cellular growth. The elongation rate of differentiating cells is inhibited by withholding water, cell expansion decreases along with decrease in turgor pressure of differentiating cells resulting in smaller cell size of shoot and roots which ultimately might lead to overall reduction in plant height stress index. Decreased cell size, induced by water limitation has been reported by several workers (Hsiao, 1973; Hanston and Hitz, 1982; Boyer 1970)

\subsection{Dry matter stress index}

The data tabulated in Table 1 in relation to dry matter stress

Table 1: Effect of water stress on plant height stress index, dry matter stress index (DMSI) and yield stability ratio under water stress of Coriandrum sativum L.

\begin{tabular}{lccc}
\hline Treatments & $\begin{array}{c}\text { Plant height } \\
\text { stress index }\end{array}$ & $\begin{array}{c}\text { Dry matter } \\
\text { stress index } \\
\text { (DMSI) }\end{array}$ & $\begin{array}{c}\text { Yield } \\
\text { stability } \\
\text { ratio }\end{array}$ \\
\hline $\mathrm{T}_{2}$ (25\% water & 94.05 & 81.42 & 88.2 \\
deficit) & -9.7 & -9.02 & -9.39 \\
$\mathrm{~T}_{3}$ (50\% water & 90.11 & 71.11 & 80.37 \\
deficit) & -9.49 & -8.43 & -8.96 \\
$\mathrm{~T}_{4}$ (75\% water & 80.34 & 56.09 & 55.55 \\
deficit) & -8.96 & -7.49 & -7.54 \\
Mean & 88.16 & 69.54 & 74.7 \\
CD ( $p=0.05)$ & 0.01 & 0.03 & 0.01 \\
\hline
\end{tabular}

(Figures in parenthesis are square root values) 
index exhibits the significant effects of different water stress. The dry matter stress index was calculated highest (81.42) for plants subjected to $25 \%$ water stress and 71.11 for $50 \%$ water stressed plants. However, minimum (56.09) was calculated for the plants, which subjected to $75 \%$ water stress level. The dry matter at the end of the seed harvest was significantly reduced by the lower watering treatment and was directly related to the watering volume of each treatment as reported by Contrearas et al. (2008) in lettuce.

\subsection{Yield stability ratio}

The perusal of data presented in table 1 indicates significant influence of different water stress treatments on yield stability ratio. It is evident from the table that the maximum yield stability ratio was found maximum i.e. $88.2 \%$ in plants subjected to $25 \%$ water stress whereas, $80.37 \%$ was registered by plants subjected to $50 \%$ water deficit. However, minimum i.e. $55.55 \%$ yield stability ratio was observed for plants subjected to $75 \%$ water stress. Ghoulam et al. (2002) also reported that a high stress magnitude reduced yield stability ratio, in case of sugar beet.

\subsection{No. of seeds plant ${ }^{1}$}

The number of seeds harvested from the unstressed and stressed plants has been presented in Table 2. Statistically significant differences were observed in number of seeds which were harvested from the unstressed plants and plant subjected to stress of different magnitude. The number of seeds plant ${ }^{-1}$ decreased with increasing water stress magnitudes as compared to control. The average number of seeds per plant in $T_{1}$ (unstressed) was found maximum i.e.1153.50 among all the treatments, which was followed by 969.18 in plants subjected to $25 \%$ water stress $\left(T_{2}\right), 787.11$ in plants subjected to $50 \%$ water stress $\left(\mathrm{T}_{3}\right)$, whereas the minimum i.e. 625.81were recorded for plants subjected to $75 \%$ water stress $\left(\mathrm{T}_{4}\right)$. Water stress when imposed at various stages, the greater reduction in growth and yield in majority of cases is observed when water stress is imposed at flowering phase. If the turgor pressure is reduced during inflorescence development, the number of flowers is reduced and possibly all reproductive efforts may be aborted, seed filling may be inhibited and fruit abscission may be enhanced ( $o^{\prime}$ Toole and Muller 1981). Our results are also in accordance with lettuce where water stress resulted in reduction in size of fruits and produced fewer seeds per plant (Tay et al., 2009).

\subsection{Seed weight plant ${ }^{-1}$}

The perusal of data in Table 2 reveals that seed weight per plant varied significantly among the unstressed and water stressed plants. Maximum seed weight per plant $6.30 \mathrm{~g}$ was registered for the unstressed plants. On the other hand the weight of seeds harvested from $75 \%$ water stressed plants was minimum $(4.46 \mathrm{~g})$ among all treatments. The plant which was subjected to 25 and $50 \%$ water stress, yielded $8.98 \mathrm{~g}$ and $6.21 \mathrm{~g}$ seed per plant respectively. So, it clear that the seed weight per plant is severely reduced at high magnitude stress, if irrigation
Table 2: Effect of water stress on yield characteristics of Coriandrum sativum $\mathrm{L}$.

\begin{tabular}{lcccc}
\hline Treatments & NSP & SWP & BY & HI \\
\hline $\mathrm{T}_{1}$ (control) & 1153.5 & 11.17 & 60.61 & 11.47 \\
& & & & -3.39 \\
$\mathrm{~T}_{2}$ (25\% water deficit) & 969.18 & 9.87 & 50.49 & 10.18 \\
& & & & -3.19 \\
$\mathrm{~T}_{3}$ (50\% water deficit) & 787.11 & 8.98 & 41.44 & 9.34 \\
& & & & -3.06 \\
$\mathrm{~T}_{4}(75 \%$ water deficit) & 625.81 & 6.21 & 31.54 & 6.55 \\
& & & & -2.56 \\
Mean & 883.9 & 9.04 & 46.01 & 9.38 \\
$\mathrm{CD}(p=0.05)$ & 106.5 & 0.84 & 0.55 & 0.03 \\
\hline
\end{tabular}

NSP: Number of seeds plant ${ }^{-1}$; SWP: Seed weight plant ${ }^{-1}$ (g); BY: Biological yield (g); HI: Harvest index (\%); (Figures in parenthesis are square root values)

is not applied during flowering and after flowering stages. Seed weight of sorghum plants was significantly affected by stress treatments in different genotypes (Abderhim et al., 2017).

\subsection{Biological yield}

Plant biological yield reduced significantly at all water stress levels below the control (unstressed) as depicted in Table 2 . The highest biological yield was achieved in control, whereas, the lowest was recorded for the plants subjected to $75 \%$ water deficit . The maximum biological yield $(60.61 \mathrm{~g})$ was registered by unstressed plants and least i.e. $31.54 \mathrm{~g}$ was observed at $75 \%$ water stress. Water stress caused decrease in biological yield as compared to non-stress condition. Biological yield is an important criterion for improvement in yield, which is strongly influenced by the environment (Kumar et al., 2001).

\subsection{Harvest index}

The data presented in Table 2 exhibits the significant effects of different water stress levels on harvest index. The harvest index ranged from $11.47 \%$ to $6.55 \%$ among different water stress treatments the highest $(11.47 \%)$ harvest index was observed in control i.e. unstressed plants However, minimum (6.55\%) harvest index was calculated for the plants, which were subjected to $75 \%$ water stress level. Bajya et al., 2017 also reported that Harvest index, as an important criterion for improvement in the yield, strongly influenced by environment. Drought susceptibility of a genotype is often measured as a function of the reduction in yield under drought stress in coriander. Biomass and harvest index showed substantial variation among the unstressed and water stress treatments of all magnitudes. Our results clearly indicate that the harvest index, and biological yield were the important traits affecting the seed yield. Water stress of 15 days duration imposed at flowering stage might have affected the translocation of solutes by altering source 
to sink relationship for assimilates.

\subsection{0 seed weight}

The percent inhibition in weight of 1000 seeds harvested from water stressed plants below unstressed ones is depicted in Figure 1. The fig indicates that the maximum inhibition of $24.5 \%$ below the control was registered for seeds harvested from $75 \%$ water stressed plants, and minimum i.e. $8.39 \%$ for $25 \%$ water deficit, whereas, moderate inhibition of $16.1 \%$ below the control was registered for $50 \%$ water stress level. Balla et al., 2013 concluded that in terms of fruit and seed yield, the flowering stage is also very sensitive to moisture stress in onion crop. The decreased 1000 seed weight obtained in our study can be assigned to the decreased seed size and seed weight because of reduced cellular expansion due to lesser water availability. In addition reduced partitioning of dry matter during seed development might be the possible cause for reduced seed weight as it is evident from our study that, quantum yield of PS II was inhibited under stress conditions.

\subsection{Seed moisture content}

The per cent decline in seed moisture content in seeds harvested from water stressed plants below unstressed ones is depicted in Figure 1. The maximum percent decline in seed moisture content i.e. $29.08 \%$ was registered by seeds which were harvested from plants subjected to the $75 \%$ water deficit, whereas, minimum decline i.e. 5.8\% below control was registered for $25 \%$ water stress treatment; seeds belonging to $50 \%$ water stress treatment registered $10 \%$ percent decline.

$25 \%$ water deficit $\square$ 50\% water deficit $75 \%$ water deficit

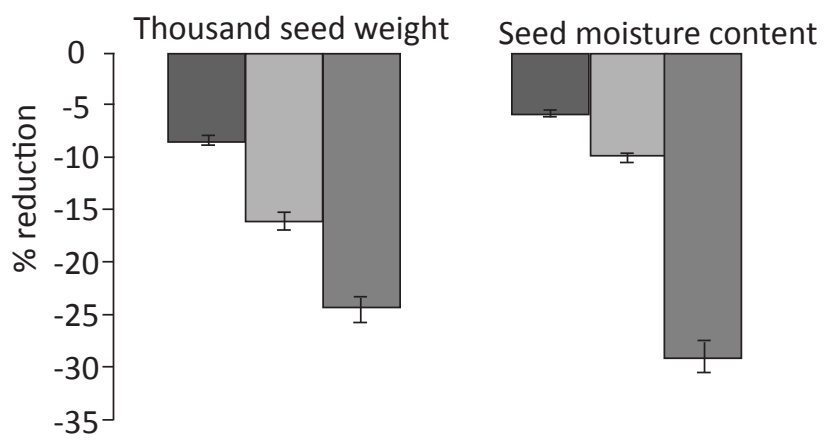

Figure 1: Percent reduction in thousand seed weight and seed moisture content of harvested seeds from stressed plants of coriander

\subsection{Solute leakage}

\subsubsection{Solute leakage after $12 \mathrm{hrs}$ and $24 \mathrm{hrs}$}

Figure 2 is depicting the percent increase in solute leakage after 12 and 24 hours of inhibition from seeds harvested from plants earlier subjected to different level of water stresses which is increasing with increasing level of water stress. It is clear from the figure 2 that higher magnitude of stress i.e. $75 \%$ water deficit resulted in maximum percent of solute
75\% water deficit $\square-50 \%$ water deficit $\triangle 25 \%$ water deficit

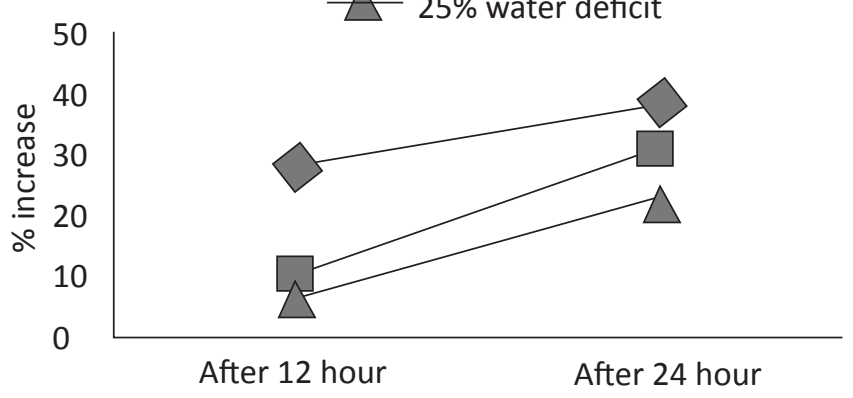

Figure 2: Percent increase in leakage of solutes after 12 and 24 hours of imbibitions from seeds harvested from stressed coriander plants

leakage i.e. $28.12 \%$ and $38.31 \%$ after 12 hours and 24 hours respectively over the control.

\subsection{Germination percentage}

The percent decrease in germination percentage was depicted in fig 3 where maximum reduction in germination percentage i.e. $21.59 \%$ was registered for $75 \%$ water deficit, followed by $50 \%$ water deficit i.e. $13.60 \%$ and $4.99 \%$ minimum was recorded for $25 \%$ water deficit. This is in agreement with the results of Balla et al., 2013 in onion.

\subsection{Mean germination time (MGT)}

The Figure 3 indicates that the maximum percent increase i.e. $49.00 \%$ above control in MGT was registered by the plants subjected to $75 \%$ water deficit which was followed by $18.33 \%$ above the control at 50\%water deficit and minimum i.e. $12.79 \%$ above the control was registered at $25 \%$ water deficit. The effect of water stress on seed quality has been investigated in maize (Khodarahmpour, 2012) and observed that the mean germination time was delayed by stress

$25 \%$ water deficit $\square$ 50\% water deficit

$75 \%$ water deficit

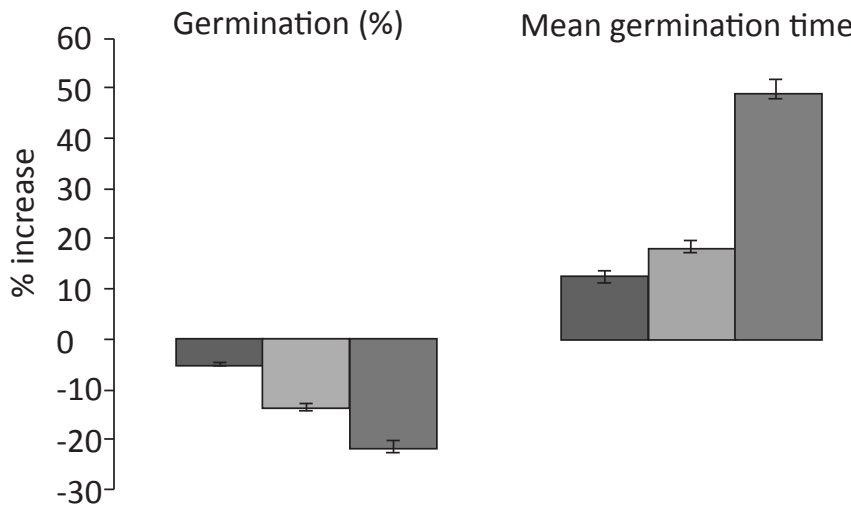

Figure 3: Percent change in seed germination percentage and mean germination time of coriander seeds harvested from stressed plants 
conditions. Water stress not only affects seed germination but also increases mean germination time in crop plants.

\section{Conclusion}

Water limitations during whole growing season had significant effects on seed yield and quality. The reduction in seed yield and quality parameters due to water deficit conditions to the mother plant at the time of seed development. Since, availability of resources in proper quantity during seed development plays a prominent and crucial in producing the good quality seed which will show better performance in field.

\section{References}

Abderhim, A. J., Ahmed, M., Naim, E., Awad, A.A, Yasin, M.D., 2017. Effect of water stress on yield and water use efficiency of sorghum (Sorghum bicolor L. Moench) in semi-arid environment. International Journal of Agriculture and Forestry 7(1), 1-6.

Bajya, M., Kakralya, B.L., Jangid, K., Burdak, A., 2017. Estimation of the effect of drought on yield and yield contributing traits in coriander genotypes (Coriandrum sativum L.). International Journal of Current Microbiology and Applied Sciences 6(8), 729-736.

Balla, M.M.A.E., Hamid, A.A., Abdelmageed, A.H.A., 2013. Effects of time of water stress on flowering, seed yield and seed quality of common onion (Allium cepa L.) under the arid tropical conditions of Sudan. Agriculture water management, 149-157.

Boyer, J.S., 1970. Leaf enlargement and metabolic rates in corn, soyabeans and sunflower at various water potentials. Plant Physiology 46, 233-235.

Contrearas, S., Bannett, M.A., Tray, D., 2008. Restricted water availability during lettuce seed production. Horticultral Science 4, 383-448.

Ghoulam, C., Foursy, A., Fares, K., 2002. Effects of salt stress on growth, inorganic ions and proline accumulation in relation to osmotic adjustment in five sugarbeet cultivars. Environmental and Experimental Botany 47, 39-50.

Hampton, J.G., Lungwangwa, A.L., Hill, K.A., 1994.The bulk conductivity test for lotus seed lots. Seed Science and Technology 22, 177-180.

Hanston, A.D., Hitz, W.D., 1982. Metabolic responses of mesophytes of plants water deficit. Annual review of plant Physiology 33, 163-203.

Hsiao, T.C., 1973. Plant responses to water stress. Annual Review Plant Physiology 24, 519-570.

Khodarahmpour, Z., 2012. Evaluation of maize (Zea mays L.) hybrids, seed germination and seedling characters in water stress conditions. African Journal of Agricultural Research 7(45), 6049-6053.

Kumar, P., Deshmukh, P.S., Kushwaha, S.R., Kumari, S., 2001. Effect of terminal drought on biomass production on its partitioning and yield of chickpea genotypes. Annals of Agriculture Research 22, 408-411.

Leena, K., Sharma, A., Lodi, S., 2012 . Potential health benefits of coriander (Coriandrum sativum L.): An overview. International Journal of Pharmaceutical Research and Development 4(2), 010-020.

O’Toole, J.C., Chang, T.T., 1979. Drought resistance in cerealsrice: a case study. In: Mussell, H., Staples, R.C. (Eds.). Stress Physiology of crop Plants. John wiley \& sons , New York, 374-405.

Singh, V.B., Singh, K., 1996. Spices, New Age Internet Private Limited Pubublication New Delhi, 100-112.

Simiciklas, K.D., Mullen, R.E., Carlson, K.A.D., 1989.Drought induced stress effect on soybean seed calcium and seed quality. Crop Science 29, 1519-1523.

Tay, D., Contreras, S., Mark, A. Bennett, J.D., Nerson, H., 2009. Red to far red ratio during seed development affects lettuce seed germinability and longevity. Horticultural Science 44(1), 130-134. 